\title{
Valores interculturales en la comunicación publicitaria internacional: un análisis cualitativo basado en corpus
}

\author{
Niels $\operatorname{POST}^{1}$ y Lieve VANGEHUCHTEN ${ }^{2}$
}

Universidad de Amberes

\begin{abstract}
RESUMEN:
Este artículo presenta los resultados de un estudio cualitativo basado en corpus en que se examinan las relaciones entre las dimensiones culturales de una comunidad lingüística y los usos léxicos, morfosintácticos y fraseológicos típicos de la misma, según los principios definidos en el modelo intercultural interdisciplinario de Guillén Nieto (2009). Este modelo se aplica en primer lugar a un corpus compuesto por los catálogos de la multinacional sueca IKEA en las versiones de habla española, holandesa e inglesa, con el fin de comprobar si las características culturales específicas de los países a los que van dirigidos los catálogos se manifiestan en sus respectivas traducciones. En segundo lugar, y con el objetivo de corroborar los resultados de la primera parte de la investigación, se comparan dichos resultados con el análisis de las formulaciones lingüísticas en catálogos de cadenas nacionales de amueblamiento, concretamente de El Corte inglés para España, Graham\&Green para Gran Bretaña y Garant Meubel para Países Bajos. Los resultados indican que el modelo de Guillén Nieto es, en efecto, un buen guión para la redacción de catálogos publicitarios respetuosos de las características culturales propias de la comunidad lingüística a la que van dirigidos. No obstante, cabe tener cuidado, tal como lo defiende de Mooij (1998), con otras variables que posiblemente influyan en el discurso publicitario así como con paradojas culturales propias de la comunidad lingüística en cuestión, ya que pueden ir en contra de los principios básicos del modelo.
\end{abstract}

PALABRAS CLAVE: marketing internacional; comunicación intercultural para fines profesionales; lingüística aplicada; discurso publicitario; análisis de corpus

TITLE: Intercultural values in international advertisement communication: a corpus-based qualitative analysis

\begin{abstract}
:
This paper comments on the results of a corpus-based qualitative analysis of the links between the cultural dimensions of a linguistic community and its lexical, morphosyntactical and phraseological uses. The analysis follows the principles of the interdisciplinary intercultural model elaborated by Guillén Nieto (2009) and applies them to a first corpus composed of three IKEA catalogues in Spanish, Dutch and English, in order to examine whether the cultural specifics of the linguistic communities they are written for, are taken into account in the translations. A second corpus contains only authentic advertising discourse coming from the same linguistic communities, and is analysed in a similar way. The results show that the model of Guillén Nieto is indeed a useful instrument to compose a text that respects the cultural identity of the target audience in its discourse. Nevertheless, the analysis also
\end{abstract}

1 Niels Post (niels.post@ua.ac.be; niels_post8@hotmail.com) es Máster en Comunicación Profesional Internacional por la Universidad de Amberes (Bélgica) y Bachelor en Filología hispánica por la Universidad de Utrecht (Países Bajos).

2 Lieve VAngehuchten (lieve.vangehuchten@ua.ac.be) es doctora en Filosofia y Letras (Lingüística española) por la Universidad católica de Lovaina-la-Nueva (Bélgica). Actualmente es profesora titular de español para fines específicos en la Universidad de Amberes (Bélgica). 
indicates that the model fails to take into account what de Mooij (1994) calls «the cultural paradox of advertising» nor other variables that may bias its basic principles.

KEY WORDS: international marketing; intercultural communication for professional purposes; applied linguistics; advertising discourse; corpus analysis

\section{1. «Act global, think local»}

En la actual corriente de «glocalización», las empresas que operan a nivel internacional optan cada vez más por un enfoque local, con conocimiento de la cultura del mercado nacional en que penetran (De Wit \& Meyer 2010 3 ; Ferraro 2010 ${ }^{4}$ ). Con respecto al ámbito del marketing, Jean-Claude Usunier (2000: $\left.453^{5}\right)$, autor de la obra Marketing across cultures, sostiene que el arte publicitario es la actividad mercadotécnica que más debe tener en cuenta la identidad cultural local de su público meta, dado que sus herramientas principales son la lengua y la comunicación. En efecto, la lengua y la comunicación constituyen componentes básicos, aunque no los únicos, de la cultura de una comunidad lingüística. Según la lengua que hablamos, y la cultura a la que pertenecemos, percibimos e interpretamos la realidad de otra manera. Basándose de esta manera en la famosa hipótesis de Sapir-Whorf acerca de la influencia de la lengua sobre la categorización de la realidad, Usunier (ibid.) argumenta que para publicistas internacionales es imprescindible no solo familiarizarse con la cultura de su público meta, sino también examinar cómo la identidad cultural se manifiesta a nivel lingüístico.

Desde una perspectiva similar, la teoría de la traducción o la traductología distingue entre las traducciones «overt» y «covert». La primera es una traducción literal, sin tener en cuenta el contexto del público meta. La segunda pretende cumplir con lo que la traductología denomina «la equivalencia funcional» (House $1997^{6}$ ). Según este principio, el receptor de una traducción debe responder al texto de manera equivalente a la manera del receptor de la versión original. Tal traducción necesita entendimiento del contexto cultural, $y$, por tanto, la ayuda de la lingüística aplicada a esta temática interdisciplinaria.

En este trabajo se pretende comprobar en qué medida el modelo lingüísticointerdisciplinario de la autora Guillén Nieto $\left(2009^{7}\right)$, basado en las dimensiones culturales de los autores Hall $\left(1976^{8}\right)$ y Hofstede $\left(2001^{9}\right)$, puede servir como herramienta a

3 De Wit, B. y Meyer, R. (2010): Strategy Synthesis. Resolving strategy paradoxes to create competitive advantage, Hampshire, Cengage Learning.

4 Ferraro, G.P. (2010): The Cultural Dimensions of International Business, London, Pearson.

5 UsUNIER, J.-C. (2000): Marketing across cultures, Harlow, Pearson Education.

6 House, J. (1997): Translation quality assessment. A model revisited, Tubingen, Gunther Narr.

7 Guillén Nieto, V. (2009): «Crossing Disciplines in Intercultural Communication Research», en Guillén Nieto, V., Marimón Llorca, C. y Vargas Sierra, Ch. (eds.), Intercultural Business Communication and Simulation and Gaming Methodology, Berlin, Peter Lang, 29-64.

8 Hall, E. T. (1976): Beyond Culture, New York, Anchor. 
la hora de preparar una versión internacional traducida de un folleto publicitario. A este propósito, se comparará el modelo de Guillén Nieto en primer lugar a los folletos publicitarios de la multinacional sueca IKEA en los países España, Gran Bretaña y Países Bajos. IKEA es el ejemplo por excelencia de una multinacional que adopta estrategias de marketing «glocales». Las tiendas y los artículos son los mismos en cualquier parte del mundo, pero su trato con el cliente no lo es. Así, IKEA opta claramente por la traducción «covert» de su catálogo, pues el objetivo es tener en cuenta la cultura local del público meta. Los autores Bordei $\left(2010^{10}\right)$ y Dagelet $\left(2011^{11}\right)$ describen en su trabajo cómo se realiza este proceso de traducción «covert» para el catálogo holandés de IKEA. El punto de partida es un texto de base redactado en inglés en 3 versiones para 3 zonas geográficas, Europa, América del Norte y Asia/Australia, pues con claras aspiraciones globales. Según el área, cada país recibe una de estas versiones con la instrucción de traducirla y adaptarla a la comunidad lingüística y cultural local. Las directivas son sencillas: la traducción debe ser informal, o sea, pertenecer al lenguaje hablado, y acercarse un máximo a la versión original. Esta directiva va además determinada por el espacio textual disponible, que no puede alejarse demasiado del bloque textual original. Durante el proceso de traducción, entre 6 y 8 colaboradores revisan la traducción y dan el feedback necesario. Se destaca, por tanto, que el proceso de traducción «covert» de IKEA está esencialmente basado en la intuición de los traductores y sus asesores.

Es el doble objetivo de este estudio realizar una corroboración empírica de este enfoque intuitivo así como comprobar la viabilidad del modelo de Guillén Nieto. A este efecto se aplicará el modelo no solo a los catálogos traducidos de IKEA sino también a los contenidos de algunos folletos auténticos, o sea no traducidos, de cadenas de amueblamiento nacionales, es decir el Corte Inglés para España, Graham\&Green para Gran Bretaña, y Garant para Países Bajos.

\section{Lingüística, antropología y marketing intercultural}

La investigación comparativa preliminar a la «exportación» intercultural de una campaña publicitaria, requiere un estudio intercultural a varios niveles. Usunier (2000: $212^{12}$ ) se basa en el trabajo de varios autores para destacar los siguientes: el análisis de la equivalencia del concepto, de la funcionalidad, de la composición de la muestra de encuestados, del proceso de la recogida de datos, de los aspectos métricos, como por ejemplo los temporales o perceptuales, y, de los aspectos lin-

\footnotetext{
9 Hofstede, G. (2001): Culture's consequences, California, Sage.

10 Bordei, A. (2010): IKEA-Una compañía multinacional en la época de la globalización. La influencia de la cultura en la comunicación publicitaria, Trabajo de investigación inédito, Barcelona, Universidad Pompeu Fabra.

11 Dagelet, A. (2011): Het afscheid van de brontekst: een onderzoek naar de toepassing van het culturele filter bij de totstandkoming van de Nederlandse IKEA catalogus. Trabajo de investigación inédito, Utrecht, Universiteit Utrecht.

12 Op.cit.
} 
güísticos. En este estudio, nos limitamos al estudio de la equivalencia de los aspectos lingüísticos, y nos basamos a tal efecto en el ya mencionado modelo lingüístico-interdisciplinario de Guillén Nieto, que comentamos a continuación.

El punto de partida del es la idea defendida por los teóricos de la comunicación intercultural de que existe un fuerte vínculo entre la lengua y la cultura de una comunidad (por ej. Clyne 1994 $4^{13}$; Agar $1995^{14}$ ). A partir de este supuesto, el modelo argumenta que la identificación de las orientaciones culturales a nivel colectivo de una comunidad, independientemente de las diferencias que puede haber a nivel individual, brinda la posibilidad al lingüista de explicar e incluso anticipar en términos culturales las preferencias lingüísticas de los miembros de esta misma comunidad, o sea en cuanto a expresiones léxicas, morfosintácticas y fraseológicas, pero también en cuanto a pragmática (estrategias comunicativas, retórica y convenciones de género). Concretamente, el modelo de Guillén Nieto combina un enfoque lingüístico con los resultados de los estudios antropológicos de Hall y Hofstede. Las dimensiones culturales descritas por estos autores constituyen la base para formular hipótesis sobre las preferencias lingüísticas.

La siguiente figura aplica dos dimensiones culturales de Hall y cuatro dimensiones de Hofstede a un contexto publicitario para los tres países estudiados en este trabajo. En la figura se formulan igualmente hipótesis basadas en el modelo de Guillén Nieto respecto de las expresiones lingüísticas propias de este mismo contexto. La selección de las dimensiones culturales recogidas en la figura se basa en su relevancia para el género estudiado, es decir el enunciado publicitario (de Mooij $1998^{15}, 2004^{16}$; de Mooij \& Hofstede $2010^{17}, 2011^{18}$; Würtz $2005^{19}$ ). En cuanto a las cifras, conviene señalar que Hofstede ofrece para sus dimensiones la posibilidad de comparar países entre sí a partir de la puntuación obtenida en cada una de las mismas (http://geert-hofstede.com/countries.html ${ }^{20}$ ).

13 Clyne, M. (1994): Inter-cultural communication at work. Cultural values in discourse, Cambridge, Cambridge University Press.

14 Agar, M. (1995): Language shock: Understanding the culture of conversation, New York, William Morrow.

15 De MooIJ, M. (1998): Global marketing and advertising. Understanding cultural paradoxes, California, Sage.

16 De MooIJ, M. (2004): «Translating Advertising. Painting the Tip of an Iceberg», The Translator, $10(2), 179-198$.

17 De Moois, M. y Hofstede, G. (2010): «The Hofstede Model. Applications to global branding and advertising strategy and research», International Journal of Advertising, 29 (1), 85-110.

18 De Mooij, M. y Hofstede, G. (2011): «Cross-Cultural Consumer behavior: A Review of Research Findings», Journal of International Consumer Marketing, 23, 181-192.

19 WüRTZ, E. (2005): «A cross-cultural analysis of websites from high-context cultures and lowcontext cultures», Journal of Computer-Mediated Communication, 11(1), article 13. http://jcmc.indiana.edu/vol11/issue1/wuertz.html

${ }_{20}$ Este enlace remite a la web oficial en donde se pueden consultar los resultados para todos los países examinados. Las dimensiones que se presentan son tanto culturales generales como propias del mundo empresarial. 
Fig. 1: Relaciones hipotéticas entre dimensiones culturales y formulaciones lingüísticas

\begin{tabular}{|c|c|c|c|}
\hline Dimensión cultural & País & Evaluación & Comportamiento lingüístico \\
\hline \multirow{3}{*}{$\begin{array}{l}\text { Tiempo (Hall) } \\
\text { Las culturas policrónicas combinan } \\
\text { varias acciones simultáneas y sin } \\
\text { restricción en el tiempo, mientras que } \\
\text { en las culturas monocrónicas las accio- } \\
\text { nes son sucesivas y puntuales. Para las } \\
\text { culturas monocrónicas el tiempo es un } \\
\text { concepto casi tangible, llevando a una } \\
\text { planificación estricta y rígida, mientras } \\
\text { que las culturas policrónicas creen que } \\
\text { las cosas sucederán naturalmente «en } \\
\text { su debido momento». Esta dimensión } \\
\text { coincide por tanto en parcialmente con } \\
\text { la Dimensión Orientación a corto/largo } \\
\text { plazo de Hofstede, razón por la cual } \\
\text { esta última no se considerará aparte en } \\
\text { este estudio. Las culturas policrónicas } \\
\text { viven sobre todo en el presente, en el } \\
\text { momento mismo, mientras que las } \\
\text { monocrónicas están planeando el } \\
\text { futuro. }\end{array}$} & ESP & policrónico & $\begin{array}{l}\text { Multifoco: } \\
\text { - Alta tolerancia de interrupciones } \\
\text { - Alta tolerancia de habla simultánea }\end{array}$ \\
\hline & GB & monocrónico & $\begin{array}{l}\text { Foco único: } \\
\text { - Baja tolerancia de interrupciones } \\
\text { - Baja tolerancia de habla simultánea }\end{array}$ \\
\hline & $\mathrm{PB}$ & monocrónico & Foco único, cf. supra \\
\hline \multirow{3}{*}{$\begin{array}{l}\text { Contexto (Hall) } \\
\text { En el mundo publicitario, las culturas } \\
\text { de contexto alto quieren crear confian- } \\
\text { za, de manera indirecta. Es lo que el } \\
\text { marketing llama soft sell strategies. Se } \\
\text { prefieren las imágenes (Würtz 2005), } \\
\text { de las que se induce gran parte de la } \\
\text { información, mientras que en las cultu- } \\
\text { ras de contexto bajo se da preferencia a } \\
\text { anuncios explícitos con mensajes } \\
\text { verbales persuasivos (hard sell). Las } \\
\text { imágenes están por lo tanto subordina- } \\
\text { das al contenido verbal. En España, } \\
\text { cultura de contexto alto, las imágenes } \\
\text { son muy importantes y se explota } \\
\text { mucho la fuerza de la metáfora visual } \\
\text { en la publicidad. En Gran Bretaña, la } \\
\text { metáfora visual será siempre explicada } \\
\text { en el texto, cf. el principio de «verbal } \\
\text { anchoring» de Phillips (2000). }\end{array}$} & ESP & bastante alto & $\begin{array}{l}\text { - Preferencia por expresiones implí- } \\
\text { citas } \\
\text { - Confianza en los índices contextua- } \\
\text { les y los códigos no verbales }\end{array}$ \\
\hline & GB & bajo & $\begin{array}{l}\text { - Preferencia por expresiones explíci- } \\
\text { tas } \\
\text {-Confianza en el lenguaje simbólico } \\
\text { y los códigos verbales }\end{array}$ \\
\hline & $\mathrm{PB}$ & bajo & Cf. supra \\
\hline \multirow{3}{*}{$\begin{array}{l}\text { Individualismo vs. Colectivismo } \\
\text { (Hofstede) } \\
\text { El discurso publicitario de una cultura } \\
\text { individualista se dirige a los consumi- } \\
\text { dores de manera muy directa y explíci- } \\
\text { ta, al contrario de la cultura colectivis- } \\
\text { ta, en que la sociedad prima sobre el } \\
\text { individuo. En Gran Bretaña es muy } \\
\text { importante sobresalir, por lo cual la } \\
\text { publicidad enfoca la posibilidad de } \\
\text { distinguirse de los demás. }\end{array}$} & ESP & medio (51) & $\begin{array}{l}\text { - Referencia a las personas como } \\
\text { miembros de un grupo. } \\
\text { - Estrategias comunicativas de } \\
\text { interdependencia }\end{array}$ \\
\hline & GB & $\begin{array}{l}\text { muy alto } \\
(89)\end{array}$ & $\begin{array}{l}\text { - Referencia a las personas como } \\
\text { seres individuales } \\
\text { - Estrategias comunicativas de } \\
\text { independencia }\end{array}$ \\
\hline & PB & alto $(80)$ & Cf. supra \\
\hline
\end{tabular}




\begin{tabular}{|c|c|c|c|}
\hline Dimensión cultural & País & Evaluación & Comportamiento lingüístico \\
\hline \multirow{3}{*}{$\begin{array}{l}\text { Distancia al poder (Hofstede) } \\
\text { Culturas marcadas por una elevada } \\
\text { distancia al poder respetan una estruc- } \\
\text { tura jerárquica de la sociedad y aceptan } \\
\text { los privilegios que acompaña el poder. } \\
\text { Estas culturas dedican por consiguiente } \\
\text { mucha importancia a los símbolos de } \\
\text { estatus en la publicidad, así como a las } \\
\text { personas mayores, como portavoces } \\
\text { que hablan con autoridad. Culturas con } \\
\text { una distancia baja al poder reaccionan } \\
\text { más bien negativamente a testimonios } \\
\text { de expertos o autoridades. }\end{array}$} & ESP & medio (57) & $\begin{array}{l}\text {-El uso de títulos en el trato con } \\
\text { personas } \\
\text {-Diferenciar entre 'tú' y 'usted' }\end{array}$ \\
\hline & GB & $\begin{array}{l}\text { bastante bajo } \\
\text { (35) }\end{array}$ & $\begin{array}{l}\text {-Omisión de títulos } \\
\text { - Ausencia de persona verbal de } \\
\text { cortesía; comunicación más informal }\end{array}$ \\
\hline & $\mathrm{PB}$ & $\begin{array}{l}\text { bastante bajo } \\
\text { (38) }\end{array}$ & $\begin{array}{l}\text { - Omisión de títulos } \\
\text { - Preferencia por 'jij' (tú) en lugar de } \\
\text { 'u' (usted) } \\
\text {-Comunicación más informal }\end{array}$ \\
\hline \multirow{3}{*}{$\begin{array}{l}\text { Masculinidad vs. Feminidad (Hofstede) } \\
\text { En el mundo publicitario, la masculini- } \\
\text { dad de una cultura se manifiesta en la } \\
\text { marcada presencia de conceptos de } \\
\text { rivalidad, concurso y ambición, mien- } \\
\text { tras que una cultura femenina dedicará } \\
\text { más interés a temas orientados hacia el } \\
\text { cuido, la harmonía y la estética. En una } \\
\text { cultura femenina, el consenso mutuo es } \\
\text { más importante que el éxito individual. }\end{array}$} & ESP & media (42) & $\begin{array}{l}\text { - Comunicación orientada hacia las } \\
\text { personas } \\
\text { - Expresiva, afectiva }\end{array}$ \\
\hline & GB & alta (66) & $\begin{array}{l}\text { - Comunicación orientada hacia la } \\
\text { tarea } \\
\text { - Instrumental, funcional }\end{array}$ \\
\hline & PB & $\begin{array}{l}\text { muy baja } \\
\text { (14) }\end{array}$ & $\begin{array}{l}\text {-Comunicación orientada hacia las } \\
\text { personas } \\
\text { - Expresiva }\end{array}$ \\
\hline \multirow{3}{*}{$\begin{array}{l}\text { Evasión de la incertidumbre (Hofstede) } \\
\text { Una cultura que busca la seguridad } \\
\text { rechaza los cambios y fomenta la } \\
\text { estructuración de la sociedad. De ahí } \\
\text { que prefiera los anuncios publicitarios } \\
\text { en que se da mucha información sobre } \\
\text { el producto, con testimonios de exper- } \\
\text { tos. También son culturas que dan } \\
\text { mucha importancia al sueño, ya que les } \\
\text { permite escaparse a un mundo ideal, sin } \\
\text { malas sorpresas. }\end{array}$} & ESP & alta (86) & $\begin{array}{l}\text { - Muchas explicaciones e informa- } \\
\text { ciones } \\
\text { - Frases complejas y largas } \\
\text { - El objetivo del mensaje solo se } \\
\text { menciona de manera indirecta }\end{array}$ \\
\hline & GB & baja (35) & $\begin{array}{l}\text { - Pocas explicaciones e informacio- } \\
\text { nes } \\
\text { - Frases sencillas y breves } \\
\text { - El objetivo del mensaje se mencio- } \\
\text { na de manera directa }\end{array}$ \\
\hline & PB & $\begin{array}{l}\text { bastante baja } \\
\text { (53) }\end{array}$ & $\begin{array}{l}\text { - Pocas explicaciones e informacio- } \\
\text { nes } \\
\text { - Frases sencillas y breves } \\
\text { - El objetivo del mensaje se mencio- } \\
\text { na de manera directa }\end{array}$ \\
\hline
\end{tabular}

La autora holandesa de Mooij $\left(1998^{21}\right)$, especialista en marketing intercultural, advierte no obstante de lo que ella denomina «la paradoja cultural de la publicidad», término con el cual se refiere al hecho de que los anuncios publicitarios reflejan lo deseado, lo ideal, y no tanto la realidad tal como es. Por consiguiente, la publicidad puede revelar valores culturales contrastantes con los vigentes. de Mooij $\left(2010: 103^{22}\right)$ da el ejemplo del uso de imágenes de familias reunidas en la mesa para compartir una comida en sociedades que manifiestan un alto individualismo. El uso de estas imágenes puede ser la expresión de un valor que se percibe como en

\footnotetext{
21 Op.cit.

22 Op.cit.
} 
vías de desaparición, y que se debe considerar por tanto como un lujo, como algo especial que será fomentado por la compra del producto.

\section{Método y corpus: análisis contrastivo de textos publicitarios de cadenas de amueblamiento}

Con el objetivo de corroborar los contenidos del esquema elaborado en el párrafo anterior, se adoptó el método descrito en Ten Thije \& Deen (2009: 92 $2^{23}$ ) para la investigación lingüística intercultural, y se realizó un análisis cualitativo y contrastivo de los folletos on line de la multinacional sueca IKEA en sus versiones traducidas al castellano, inglés y holandés para España, Gran Bretaña y Holanda. Asimismo, para comprobar la efectividad del esquema como herramienta o pauta a la hora de redactar la versión internacional de un texto publicitario, se examinaron y compararon los folletos publicitarios de algunas cadenas de amueblamiento nacionales de España (ESP), Gran Bretaña (GB) y Países Bajos (PB). La selección de estos tres países se justifica por el conocimiento de ambos autores de los idiomas nacionales hablados en los mismos, así como por el hecho de que, según la bibliografía especializada (Hofstede 2001 ${ }^{24}$; Usunier \& Sissmann $1986^{25}$ ), se consideran como pertenecientes a distintas zonas de afinidad cultural, una condición necesaria para el análisis contrastivo. En cuanto al tamaño, cabe señalar que la extensión de los catálogos de IKEA es de 300 páginas en las tres versiones. El corpus nacional no demuestra este equilibrio en cuanto a extensión: el catálogo de El Corte Inglés es bastante más grande (200 páginas) que el corpus de Graham \& Green (34 páginas) y Garant (22 páginas), lo cual supone por supuesto una limitación en cuanto a la representatividad de los resultados del corpus nacional.

A continuación se presentan los resultados del análisis que se basa en el estudio de los datos empíricos del corpus y que de esta manera permite describir, en primer lugar, cómo los enunciados publicitarios de distintas comunidades revelan ciertos aspectos de sus culturas a través de las formulaciones lingüísticas, y, en segundo lugar, cuáles son las particularidades de dichas formulaciones.

23 Ten ThiJe, J. y DeEN, J. (2009): «Interculturele communicatie: contrast, interactie en transfer», Tijdschrift voor toegepaste taalwetenschap, 91-105.

24 Op.cit.

25 Usunier, J.C. y SisSMANN, P. (1986) : «L'interculturel au service du marketing», HarvardL'Expansion, 40, 80-92. 


\section{Nacional vs. Multinacional: unos resultados}

\subsection{El análisis de las versiones holandesa, española e inglesa del catálogo de IKEA}

En lo que sigue se comparan las hipótesis iniciales con las versiones neerlandesa, inglesa y española de la multinacional IKEA. El objetivo de esta comparación es la corroboración del modelo como herramienta de ayuda a una traducción que responde en sus formulaciones lingüísticas a los valores culturales de su público meta.

Fig. 2: Comparación de las versiones internacionales de la multinacional IKEA

\begin{tabular}{|l|l|l|l|}
\hline \multicolumn{5}{|c|}{ IKEA } \\
\hline Dimensiones & Países Bajos & España & Gran Bretaña \\
\hline Tiempo & - & Policrónico & Monocrónico \\
\hline Contexto & Bajo & Alto & Bajo \\
\hline Individualismo & Individualista & Colectivista & Individualista \\
\hline Distancia al poder & Baja & Baja & Baja \\
\hline Masculinidad & Masculina/Femenina & Masculina/Femenina & Masculina/Femenina \\
\hline $\begin{array}{l}\text { Evasión de la } \\
\text { incertidumbre }\end{array}$ & Baja & Alta & Baja \\
\hline
\end{tabular}

De la figura 2 se desprende que la mayoría de las dimensiones culturales concuerda con las hipótesis iniciales. Ilustramos esta observación con un ejemplo concreto:

Fig. 3: Un ejemplo
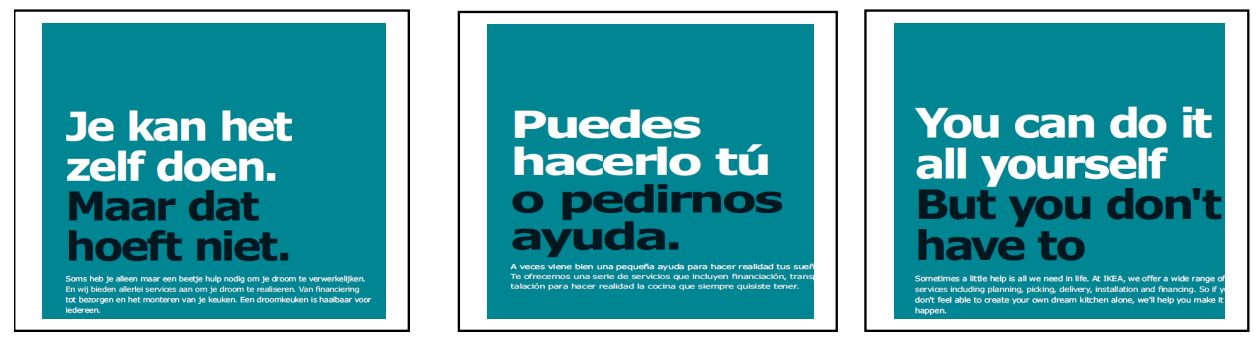

En los eslóganes citados, la versión española manifiesta una formulación claramente colectivista, gracias al uso del pronombre personal COI 'nos' en combinación con el verbo transitivo 'pedir' y la semántica del sustantivo 'ayuda'. En las versiones holandesas (Puedes hacerlo tú. Pero no hace falta) e inglesas (Puedes hacerlo tú pero no debes hacerlo), no obstante, constatamos que la formulación 
individualista se mantiene en todo el eslogan, gracias a una expresión intransitiva con un verbo modal.

Asimismo, la versión inglesa manifiesta expresiones propias de una cultura de contexto bajo, por el uso de formulaciones explícitas por un lado, y de lenguaje simbólico, por otro. El eslogan con doble sentido "Small-minded? Absolutely. In a good way" hace a la vez referencia a la cualidad negativa que es la mezquindad, como al significado literal de saber aprovechar los espacios pequeños. Un juego de palabras sobre esta misma idea se encuentra en el siguiente ejemplo: "All you really need is an open mind and a bit of clever small-scale thinking."

En cuanto a la dimensión Distancia al poder, IKEA opta en cada versión internacional por una distancia baja, lo cual se manifiesta en el uso del tuteo en español y holandés (irrelevante para el inglés debido a la inexistencia de una persona verbal de cortesía) y también en eslóganes como "See democracy in action at IKEA.co.uk/smallspace". No obstante, la versión española es la única que abre el catálogo con una presentación personal: "Antes de contaros las novedades de este nuevo catálogo, me gustaría presentarme. Mi nombre es Belén Frau y, desde el 1 de septiembre, soy la nueva directora general de IKEA Ibérica." Esta presentación corresponde con los rasgos jerárquicos de una sociedad marcada por una alta Distancia al poder.

Otra dimensión en la que IKEA no concuerda con las hipótesis iniciales es la de masculinidad/feminidad, ya que en sus versiones internacionales quiere transmitir de manera unívoca que su misión es ser funcional a la vez de solícita, pues igual de masculina que femenina. Por tanto, prima en cuanto a esta dimensión la cultura empresarial sobre la nacional, como se puede ver en los siguientes ejemplos sacados del texto español: "En IKEA utilizamos recursos prácticos y económicos." vs. "En IKEA creemos que los niños tienen derecho a jugar, a aprender y a desarrollarse." o "Pero el cultivo del algodón puede tener un alto coste para las personas y el medio ambiente: en muchos casos los niños no acuden a la escuela porque tienen que trabajar en el campo y se utilizan grandes cantidades de agua y productos químicos. Parte de este proyecto también consiste en crear cambios reales y duraderos para los niños de las comunidades donde se cultiva el algodón". Cabe observar aquí el uso de frases explicativas muy largas, un rasgo ausente en los textos de El Corte Inglés, por la importancia mayor de las imágenes.

La dimensión Tiempo tampoco está muy presente, aunque algo más que en los textos de las cadenas nacionales. En la versión inglesa, las expresiones cumplen con la hipótesis de Tiempo monocrónico, mientras que en la versión española se manifiesta el carácter policrónico del tiempo en el siguiente ejemplo: “...relajaros juntos, mientras cada uno realiza sus actividades". Más ejemplos del análisis contrastivo de las tres versiones del catálogo de IKEA se dan a continuación: 
Grootse ideeën voor kleine ruimtes (pag. 4) (Grandes ideas para espacios pequeños)

-Título concreto y explícito (Bajo contexto)

- El consumidor es tratado como individuo: "Een slimme indeling maken met jouw persoonlijke stijl?" (Un amueblamiento inteligente con tu propio estilo?) (Individualismo)

- Tuteo. (Baja distancia al poder)

- Frases y explicaciones breves, sin mucha información: "Zou je meer willen doen met de ruimte die je hebt?”... “Wij geloven dat het kan.” (¿Quieres hacer más con tu espacio? Nosotros creemos que es posible.) (Baja evasión de la incertidumbre)

- "Dat lijkt vragen om moeilijkheden, maar als iedereen goed samenwerkt, is bijna alles mogelijk." (Eso parece complicado, pero gracias a un buen trabajo de equipo, todo es posible): Una expresión que está orientada al factor humano en el trabajo, lo cual indica Feminidad

\section{Bienvenido al mundo de las pequeñas/grandes ideas (pag. 4)}

- Un título implícito que no hace referencia a los espacios que amueblar o decorar (Alto contexto)

- Individualismo: “Qué te parece sacar partido al espacio disponible y utilizarlo de manera más práctica y personal"

- Tuteo: poca distancia al poder

- Frases largas con mucha información: "Sólo necesitas tener la mente abierta y unas cuantas pequeñas/grandes ideas: aprovechar espacios inesperados y elegir muebles que cumplan más de una función" (Evasión de la incertidumbre)

- Énfasis en el aspecto humano: "Podríamos pensar que sería un desastre, pero es la prueba de que nada es imposible, cuando se trabaja en equipo." (Feminidad)

\section{Small-minded? Absolutely. In a good way! (pag. 4)}

- Uso de lenguaje figurado con un doble sentido, típico de culturas de Bajo contexto, que integran un máximo de los sentidos en la expresión verbal, más que en el contexto no verbal o extralingüístico.

-Trato del consumidor como un ser individual, independiente e inteligente "All you really need

is an open mind and a bit of clever small-scale thinking." (Individualismo)

- "See democracy in action at IKEA.co.uk/smallspace" (Baja distancia al poder)

- Frases breves: "Take a look, over the next few pages, at how we tackled six small spaces." (Baja evasión de incertidumbre)

- Tanto expresiones de Masculinidad como de Feminidad: "It's all about finding and using hidden spaces, or choosing furniture that does more than one job." (masculino) vs. "That might seem like a recipe for disaster, but it proves that when everything - and everyone works together, almost anything is possible." (Femenino)

\section{Ontmoet elkaar in het midden (pag. 12) (Encontraos en el centro)}

- Esta expresión tiene un doble sentido por referirse literalmente al centro del espacio, pero también por hacer a la vez alusión a expresiones fraseológicas en holandés, que son 'de gulden middenweg' o 'de kerk in het midden houden', refiriéndose a la fuerza de la cultura del consenso. La expresión es, por consiguiente, una manifestación de una cultura de Bajo 
contexto, que integra el contenido de las ideas en el mensaje verbal.

- Trato del consumidor como una pareja de individuos: cada uno con sus gustos (Individualismo)

¿Quedamos en el centro! (pag. 12)

- El título tiene un significado literal y se dirige a los consumidores como un grupo, mediante el uso de la 1era persona del plural (Alto contexto y Colectivismo)

Meet in the middle (pag. 12)

Igual que en la versión holandesa, el título tiene un doble sentido (Bajo contexto).

Niet alleen mooi om op te zitten. (pag 28) (No solo bonito para sentarse)

- Muy explícito. (Bajo contexto)

- Una clara referencia a la cultura de la empresa :"We hebben een eenvoudige filosofie wat betreft meubels." (Tenemos una filosofía sencilla por lo que se refiere a los muebles.)

La mejor calidad a precios aún más bajos (pag. 28)

- Implícito, sin referencia a la funcionalidad del mueble (Alto contexto)

- "Así que cuando nosotros ahorramos, tú ahorras." (Colectivismo)

- Una clara referencia a la supuesta cultura del grupo meta, mediante el uso de la palabra

'siesta': "Los sofás EKTORP son capaces de aguantar un montón de siestas y mantenerse como nuevos."

And the living is easy... (pag. 28)

- Título con sentido figurado, ya que usado como expresión fraseológica, con reminiscencia

a, por ejemplo, la canción «Summertime, and the livin' is easy...» (G. Gershwin)

- Clara referencia a la cultura de funcionalidad y eficacia de la empresa: "To make sure you can enjoy it in your home, we've designed the range in 2-seat, 3-seat, sofa bed and chaise longue options."

Verbeter de wereld. Begin bij jezelf. (pag. 87) (Mejora el mundo. Empieza contigo mismo.)

- Clara referencia a la responsabilidad individual de cada consumidor (Individualismo) -Pocas explicaciones y frases breves: Baja evasión de la incertidumbre

Hacer bien nuestro trabajo ayuda a que los niños tengan un futuro mejor. (pag 87)

- Colectivismo, por la referencia a la responsabilidad común

- Largas frases, con muchas explicaciones sobre el porqué: "Utilizamos mucho algodón para fabricar desde ropa de cama hasta fundas para sillas, porque nos gusta la sensación de confort que ofrece. Pero el cultivo del algodón puede tener un alto coste para las personas y el medio ambiente: en muchos casos los niños no acuden a la escuela porque tienen que trabajar en el campo y se utilizan grandes cantidades de agua y productos químicos. Parte de este proyecto también consiste en crear cambios reales y duraderos para los niños de las comunidades donde se cultiva el algodón.” (Alta evasión de la incertidumbre)

Saving the planet is top of our list of priorities, too (pag. 87)

- Referencia explícita a la responsabilidad social y ética de la empresa (Bajo contexto)

-Frases breves: "We love the natural qualities of cotton". (Baja evasion de la incertidumbre)

- Formulación explícita y concise del objetivo del proyecto: "The aim is to help cotton producing communties to earn a decent living, and enjoy a healthy life, with access to education.” (Masculinidad). 


\subsection{El análisis de los catálogos de las cadenas nacionales}

En lo que sigue se presentarán los resultados del análisis de los folletos de las cadenas nacionales. De la figura que se presenta a continuación se desprende que los resultados para Gran Bretaña y Países Bajos concuerdan en casi todas las características culturales y lingüísticas formuladas de manera hipotética en la figura 1 del apartado 2.

Fig. 4: Comparación de las cadenas nacionales

\begin{tabular}{|l|l|l|l|}
\hline \multicolumn{5}{|c|}{ Cadenas nacionales } & Gran Bretaña \\
\hline Dimensiones & Países Bajos & España & Monocrónico \\
\hline Tiempo & - & - & Bajo \\
\hline Contexto & Bajo & Alto & Individualista \\
\hline Individualismo & Individualista & Colectivista/Individualista & Alta/Baja \\
\hline Distancia al poder & Alta & Alta/Baja & Femenina \\
\hline Masculini-/feminidad & Femenina & Femenina & Baja \\
\hline $\begin{array}{l}\text { Evasión de la incerti- } \\
\text { dumbre }\end{array}$ & Alta/Baja & Baja & . \\
\hline
\end{tabular}

Para Gran Bretaña la concordancia es casi total: la dimensión Distancia al poder tiene tanto manifestaciones de una Alta distancia, sobre todo debido al uso de adjetivos calificativos que destacan el carácter prestigioso de los muebles, como de una Baja distancia, por el registro informal y el estilo muy directo en que se usan muchos imperativos. El resultado más llamativo del análisis concierne la dimensión Masculini$\mathrm{dad} /$ Feminidad. Según los resultados de Hofstede, la sociedad británica es claramente masculina, con un resultado muy elevado de 66 (http://geerthofstede.com/countries.html). Una sociedad masculina vive para trabajar, con un profundo afán de superación en todo lo que se emprende. El objetivo de la vida es tener éxito. Esta dimensión no se ve corroborada por los resultados en absoluto. Los datos empíricos manifiestan un discurso que aboga por valores no materiales, que producen una felicidad duradera, en lugar de placeres fugaces. Esta discrepancia tan importante se debe probablemente a la paradoja cultural de la publicidad, a la que ya se ha referido con antelación, y como se demostrará ahora en los ejemplos. 


\section{Graham \& Green (GB)}

Oversized Bulb Vase. (pag. 1)

"Brighten up your life with a bloom in a light bulb! These eccentric vases add fun to tablescapes. Please note, the silver does oxidize after usage which adds to the vintage charm."

- Título explícito y literal (Bajo contexto)

- Enumeración de frases breves, lo cual indica una Baja evasión de la incertidumbre

- "Brighten up your life" (Individualismo)

- "Brighten, light, fun": palabras que no hablan de la funcionalidad del florero, sino de su efecto emocional para el propietario (Feminidad)

- "Please note, the silver does oxidize after usage" (Orientación a largo plazo)

- "Eccentric, vintage charm" (indicación de prestigio: Alta distancia al poder)

\section{Louise Graham (pag. 2)}

"My most treasured object is an oil painting belonging to my mother, a much-loved gift from my father. It depicts a woman milking a cow in the fields. It hung in our sitting room above the fireplace and now hangs above ours. For my mother, who grew up in the country, it

brought her back. For me, it brings back part of my mother.

At Graham and Green, we're not fans of the flat-pack, throw away generation. But before you

conjure up images of mad hoarders know that we believe our products are worth saving up for

$\&$ getting sentimental about. We like to think you'll choose wisely, hold on to them for a very

long time \& hand them down to generations to come. A home is built on love, and somehow

these sentimental feelings seep into our possessions making them more valuable; less material.

[...] Amongst our largest collection of new products, we believe you'll find something to make your own memories with."

-El catálogo abre con un prólogo de una fundadora de Graham \& Green. La autora es femenina, y, en efecto, esta Feminidad se confirma en varios aspectos. Priman los valores sentimentales de los muebles sobre los materiales y funcionales (nada de «usar y tirar», nada de «flat-pack»). La metáfora "A home is built on love" tiene como objetivo conceptual de convencer al consumidor de qué es realmente importante, y que vale la pena ahorrar por ello: "worth saving up for", porque es algo sin precio, con un valor inestimable, por lo cual siempre será un buen negocio. La metáfora se explica igualmente verbalmente y explícitamente, lo que es propio de un Bajo contexto (cf. principio de «verbal anchoring» de Phillips 2000).

- La evocación del tiempo es monocrónica: se evocan varias generaciones de manera sucesiva, la pasada, la presente, la futura, y cada una, en su tiempo, sacó, saca y sacará provecho de un mueble duradero.

- Se insiste mucho en el aspecto duradero de los muebles, lo que se manifiesta en sintagmas como "for a very long time", "for generations to come", "making them more valuable": Orientación a largo plazo. 
-El trato es directo e individual: "We like to think you'll choose wisely", con confianza en el buen sentido de sus consumidores (Individualismo).

- Registro informal, con expresiones coloquiales, como "we're not fans of", "throw-away generation" (Baja distancia al poder)

Go global and get an ethnic cane chair with fluorescent nylon string detail for a hot summer update.

Hard wearing melamine for outdoor dining. Pack a set of these in your picnic for alfresco dining

Inject some Florida fun with our fabulous colour pop lattice iron lanterns. (pag. 5)

-estilo muy directo y explícito, con imperativos esloganescos "Go global" (Bajo contexto)

- frases breves, pero muchas: cada foto va acompañada de por lo menos un texto (Bajo contexto y Baja evasión de la incertidumbre)

- registro informal (Baja distancia al poder)

- referencias a viajes caros en el extranjero (culturas étnicas, Florida) (Alta distancia al poder, por los símbolos de estatus que suponen)

En cuanto a Países Bajos las diferencias se limitan a la ausencia de expresiones relacionadas con el tiempo, así como al uso sistemático de la forma de cortesía 'Usted', lo cual es en principio una indicación de una alta distancia al poder. No obstante, la preferencia de la forma de cortesía en un contexto publicitario holandés se debe relativizar, en el sentido de que existe en la lengua holandés un refrán muy famoso que es «Klant is Koning» (El Cliente es Rey), lo cual puede explicar por qué se prefiere un trato más formal en la publicidad holandesa, en oposición con otras áreas de la sociedad en que es más común dar preferencia al tuteo, en correspondencia con los resultados de los estudios de Hofstede que indican para Países Bajos una Distancia al poder más bien baja.

\section{Garant Meubel (PB)}

\section{ALOS (pag. 2)}

"Tijdloos vormgegeven bank met diverse armleuningen en poten verkrijgbaar. 2,5 zits vast vanaf 859.-

Fauteuil met topswing vanaf 655."

(Sofá de forma atemporal disponible con diversos apoyabrazos y patas. 2,5 asientos fijos a partir de 859,-. Sillón con topswing desde 655,-)

- Texto muy explícito, con referencia a las posibilidades de diseño del banco. Expresión propia de una cultura de contexto bajo.

\section{Hubert (pag. 3)}

- Texto explícito con uso de adjetivos calificativos para crear un ambiente cálido: "eigentijds" (contemporáneo), "houtkleuren" (colores de madera), "smaakvol." (de buen gusto) y con un contenido claro y directo, que comenta las ventajas de los muebles (Contexo bajo)

- Al consumidor se le trata de 'Usted' (Alta distancia de poder)

- Frases concisas, sin explicaciones complejas (Baja evasión de la incertidumbre )

Creëer uw eigen bank (pag. 5) (Cree su propio sofá)

"Kortom voor ieder moment van de dag en voor iedere sfeer waarin u zich begeeft..."

(En suma, para cualquier momento del día y cualquier ambiente...) 
-Expresión de feminidad, que se refiere al hecho de estar a gusto en su hogar, más que a la funcionalidad.

\section{Eldrick (pag. 7)}

"... geheel naar eigen wens samen te stellen"

(... a componer enteramente según su propio gusto)

-Individualismo

Para la publicidad de España, los resultados del análisis indican que solo hay concordancia con las hipótesis en cuanto a la dimensión Contexto. En efecto, la sociedad española se caracteriza por una comunicación implícita, lo cual se manifiesta en el género publicitario por un uso pronunciado de imágenes, en detrimento del texto que las acompaña. Según Hermeking (2005: 205 ${ }^{26}$ ) esto es una característica de las culturas femeninas, que valoran las relaciones de confianza, y que dan, por tanto, en la publicidad prioridad a las imágenes (soft sell strategy), más que al discurso persuasivo (hard sell). Würtz $\left(2005^{27}\right)$ constata algo parecido en su análisis de páginas web y lo interpreta como una preferencia de las culturas de Alto contexto.

Por otro lado, los análisis para la publicidad de Países Bajos confirman la dimensión cultural de feminidad a pesar de que las imágenes están bastante menos presentes que en el folleto de El Corte Inglés. En efecto, los textos en neerlandés tienen, más que una finalidad persuasiva, la función de crear un ambiente hogareño, acogedor, algo que en neerlandés se expresa mediante el sustantivo «gezelligheid», concepto sin traducción en español o inglés, pero muy importante y muy presente en la cultura y lengua holandesas. Pero la dimensión Feminidad se manifiesta también, tanto en los textos holandeses como españoles, en las expresiones de cuido, por ejemplo "Donde te refugies y des refugio." o "Así conseguirás que tu casa sea un lugar donde disfrutes y hagas disfrutar."

El resultado «alto-bajo» del folleto de España para la dimensión Distancia al poder se debe al tuteo sistemático y explícito, por ejemplo: "Si éste es tu mundo, no lo dudes, apuesta decididamente por él." Por otro lado, la distancia a poder sí se manifiesta en las referencias al deseo de estatus y prestigio, mediante el uso del léxico apropiado: “... marcas exclusivas, las firmas especializadas de más prestigio...".

Con todo, estos resultados permiten entender por qué algunas dimensiones culturales son de escasa representación lingüística en el texto español. Así, el resultado para la dimensión Evasión de la incertidumbre, que en principio para España es alta, en oposición con lo que demuestra el análisis, se puede explicar por la primacía de las imágenes sobre las explicaciones, tanto más que los muebles en general

26 Hermeking, M. (2005): «Culture and Internet consumption: Contributions from cross-cultural marketing and advertising research», Journal of Computer-Mediated Communication, 11(1), article 10. http://jcmc.indiana.edu/vol11/issue1/hermeking.html

27 Op. Cit. 
no necesitan de muchas explicaciones sobre su uso o seguridad. A partir de estos resultados, se puede por tanto formular la hipótesis de que, según el género textual, algunas dimensiones se manifiestan más que otras, por lo cual merman la presencia de otros elementos lingüísticos.

En cuanto a la dimensión de individualismo/colectivismo, cabe observar que el folleto de El Corte Inglés contiene tanto expresiones colectivistas, en correspondencia con las hipótesis iniciales, como individualistas. Este resultado ambiguo se explica con el concepto de paradoja cultural de de Mooij: la sociedad española es tradicionalmente colectivista, con familias enteras viviendo bajo el mismo techo por necesidad económica, pero eso no impide que los españoles sueñen con su propia casa, decorada y amueblada según sus gustos personales. Esta realidad muy bien puede explicar la presencia de expresiones lingüísticas propias del individualismo, por ejemplo "Te ofrecemos cocinas completamente personalizadas, ajustadas a tu gusto y a tu presupuesto." o "Pon una pausa en tu ajetreado ritmo", como del colectivismo, por ejemplo "Te hará feliz a ti y, también, a los que compartan tu vida." o "Es un estilo cálido, familiar".

\section{El Corte Inglés (ESP)}

\section{Decora (pag. 2)}

"DECORA es tu puerta de entrada a un mundo libre en decoración."

-Evasión de la incertidumbre, evocación de otro mundo, de la libertad, como en un sueño

\section{Muebles (pag. 5)}

"Crea un mundo donde te sientas realmente a gusto."

-Expresión de feminidad, el objetivo es estar cómodo, sin referencia explícita a la funcionalidad

- Trato informal (Baja distancia al poder) e individual

\section{Urban chic (pag. 6)}

"Es un estilo que surge de la cultura urbana"

-Expresión de prestigio, de estatus, propia de una Alta distancia al poder, también en el título por la combinación de 2 otros idiomas de prestigio: 'urban' del inglés y 'chic' del francés

Urban Class (pag. 68)

"Lo clásico renovado e integrado en un lenguaje decorativo actual tiene mucho futuro."

- Evasión de la incertidumbre: el futuro y el éxito están asegurados.

- Alta distancia al poder, con referencia al prestigio y el estatus

\section{Mesa y cocina (pag. 154)}

"Desde lo más tradicional a lo más moderno."

- Paradoja Innovación/Estabilidad

La cocina que sueñas, a tu alcance (pag. 196)

- Evasión de la incertidumbre, Individualismo, Baja distancia al poder 


\section{Conclusión}

En este artículo se han presentado los resultados de un estudio cualitativo y contrastivo de textos publicitarios en que se examinan las relaciones entre las dimensiones culturales de una comunidad lingüística y los usos léxicos, morfosintácticos y fraseológicos típicos de la misma, tal como las sugiere el modelo intercultural interdisciplinario de Guillén Nieto. Los análisis se han realizado en primer lugar en un corpus compuesto por los catálogos de la multinacional sueca IKEA en las versiones de habla española, holandesa e inglesa con el fin de comprobar si las características culturales específicas de los países a los que van dirigidos los catálogos se manifiestan en sus respectivas traducciones dichas «covert». En segundo lugar, se han examinado folletos publicitarios de cadenas nacionales de amueblamiento para los países España, Gran Bretaña y Holanda con objeto de corroborar los resultados de la primera parte de la investigación.

Tal como se puede observar en la siguiente figura de síntesis, los resultados indican que el modelo elaborado según los principios de Guillén Nieto es, en efecto, un buen guión para la redacción y revisión de catálogos publicitarios respetuosos de las características culturales propias de la comunidad lingüística a la que van dirigidos. Los contenidos de los catálogos tanto nacionales como traducidos manifiestan en gran medida las dimensiones culturales y sus correspondientes formulaciones lingüísticas sugeridas por el modelo.

Fig. 5: Síntesis de los resultados

\begin{tabular}{|l|l|l|l|l|l|l|}
\hline Dimensiones & $\begin{array}{l}\text { IKEA } \\
\text { PB }\end{array}$ & $\begin{array}{l}\text { IKEA } \\
\text { ESP }\end{array}$ & $\begin{array}{l}\text { IKEA } \\
\text { GB }\end{array}$ & $\begin{array}{l}\text { Garant } \\
\text { PB }\end{array}$ & $\begin{array}{l}\text { El Corte Inglés } \\
\text { ESP }\end{array}$ & $\begin{array}{l}\text { G\&G } \\
\text { GB }\end{array}$ \\
\hline Tiempo & - & Sí & Sí & - & - & Sí \\
\hline Contexto & Sí & Sí & Sí & Sí & Sí & Sí \\
\hline Individualismo & Sí & Sí & Sí & Sí & No & Sí \\
\hline Distancia al poder & Sí & No & Sí & No & No & Sí \\
\hline Masculinidad & Sí & No & No & Sí & Sí & No \\
\hline $\begin{array}{l}\text { Evasión de la incer- } \\
\text { tidumbre }\end{array}$ & Sí & Sí & Sí & No & No & Sí \\
\hline
\end{tabular}

No obstante, cabe tener cuidado, tal como defiende de Mooij, con posibles dominaciones de ciertas dimensiones sobre otras, así como con paradojas culturales propias de la comunidad lingüística en cuestión, ya que pueden ir en contra de los principios básicos del modelo. Concretamente se ha constatado en el corpus nacional la primacía de imágenes en culturas de alto contexto, como la española, sobre 
los textos, así como un creciente individualismo en el género publicitario español, sin duda para responder al «sueño» de un hogar propio, que no se debe compartir con una familia compuesta de varias generaciones. Por otro lado, se manifiesta en el corpus inglés un claro deseo de feminidad y de todos los valores que se le adjudican, como el amor, los sentimientos, la familia, la serenidad. El texto inglés insiste en que los objetos con valor sentimental primen sobre su valor material, es decir, el precio. Ahora bien, tal como hemos destacado en el apartado 3 de este artículo, antes de poder generalizar estas conclusiones, sería conveniente ampliar el corpus nacional con el fin de llegar a un equilibrio en cuanto a tamaño e incrementar de esta manera su representatividad.

Otra constatación importante proviene del análisis del corpus traducido y concierne la presencia de ciertos valores culturales de la empresa matriz en la versión «exportada». En el caso concreto de IKEA, llama la atención que, a pesar de que sus tiendas parecen idénticas por todas partes, cualquiera sea el país, la multinacional hace un esfuerzo marcado por tener en cuenta las expresiones lingüísticas propias de la cultura local a la que se dirige. No obstante, en este ejercicio IKEA no pierde ninguna oportunidad para hacer hincapié sobre sus propios valores culturales y éticos, por ejemplo en cuanto a sostenibilidad o accesibilidad de sus productos.

Finalmente, estimamos que los resultados de este artículo refuerzan la idea de que un análisis interdisciplinario basado en la antropología y la lingüística aplicada aporta una valiosa ayuda a la hora de traducir un texto publicitario a otra cultura, y eso tanto para los especialistas de marketing que deben concebir la operación de «exportación» de la campaña en su totalidad, como para los traductores que deben realizar la parte lingüística, con todo lo que conlleva.

\section{Referencias bibliográficas}

Fuentes primarias (última consulta el $28-08-2012$ ):

http://onlinecatalogue.ikea.com/NL/n1/2012/IKEA_Catalogue/

http://onlinecatalogue.ikea.com/ES/es/2012/IKEA_Catalogue/

http://onlinecatalogue.ikea.com/GB/en/2012/IKEA_Catalogue/

http://www.garantmeubel.nl/

http://elcorteingles.papelaweb.com/elcorteingles/decora/papelaweb.php?cm_sp=eci-_-

catalogos-_-decoraOI1112

http://www.grahamandgreen.co.uk/catalogue.pdf

Fuentes secundarias:

AGAR, M. (1995): Language shock: Understanding the culture of conversation, New York, William Morrow. 
BordeI, A. (2010): IKEA-Una compañía multinacional en la época de la globalización. La influencia de la cultura en la comunicación publicitaria, Trabajo de investigación inédito, Barcelona, Universidad Pompeu Fabra.

Clyne, M. (1994): Inter-cultural communication at work. Cultural values in discourse, Cambridge, Cambridge University Press.

DAGELET, A. (2011): Het afscheid van de brontekst: een onderzoek naar de toepassing van het culturele filter bij de totstandkoming van de Nederlandse IKEA catalogus. Trabajo de investigación inédito, Utrecht, Universiteit Utrecht.

DE MoOIJ, M. (1998): Global marketing and advertising. Understanding cultural paradoxes, California, Sage.

(2004): «Translating Advertising. Painting the Tip of an Iceberg», The Translator, 10 (2), 179-198.

DE Moois, M. Y Hofstede, G. (2010): «The Hofstede Model. Applications to global branding and advertising strategy and research», International Journal of Advertising, 29 (1), 85-110.

(2011): «Cross-Cultural Consumer behavior: A Review of Research Findings», Journal of International Consumer Marketing, 23, 181-192.

DE WIT, B. Y MEYER, R. (2010): Strategy Synthesis. Resolving strategy paradoxes to create competitive advantage, Hampshire, Cengage Learning.

FERRARO, G.P. (2010): The Cultural Dimensions of International Business, London, Pearson.

GuILlÉn Nieto, V. (2009): «Crossing Disciplines in Intercultural Communication Research», en Guillén Nieto, V., Marimón Llorca, C. y Vargas Sierra, Ch. (eds.), Intercultural Business Communication and Simulation and Gaming Methodology, Berlin, Peter Lang, 29-64.

HALL, E. T. (1976): Beyond Culture, New York, Anchor.

HERMEKING, M. (2005): «Culture and Internet consumption: Contributions from crosscultural marketing and advertising research», Journal of Computer-Mediated Communication, 11(1), article 10. http://jcmc.indiana.edu/voll1/issue1/hermeking.html

Hofstede, G. (2001): Culture's consequences, California, Sage.

House, J. (1997): Translation quality assessment. A model revisited, Tubingen, Gunther Narr.

PhILLIPS, B. J. (2000): «The impact of verbal anchoring on consumer response to image ads», Journal of Advertising, 29, 15-24.

TEN THIJE, J. Y DEEN, J. (2009): «Interculturele communicatie: contrast, interactie en transfer», Tijdschrift voor toegepaste taalwetenschap, 91-105.

USUNIER, J.C. (2000): Marketing across cultures, Harlow, Pearson Education.

USUNIER, J.C. Y SISSMANN, P. (1986) : «L'interculturel au service du marketing», HarvardL'Expansion, 40, 80-92.

WÜRTZ, E. (2005): «A cross-cultural analysis of websites from high-context cultures and low-context cultures», Journal of Computer-Mediated Communication, 11(1), article 13. http://jcmc.indiana.edu/vol11/issue1/wuertz.html 